20th several pieces of tendon about an inch and a half long came away from the palmar wound. On Dec. 28th sensibility was quite restored in the hand, and the pain had left the palm. On Jan. 23rd all the wounds were quite healed. The mobility of wrist was perfect. The patient had slight power of flexion in the fingers, most marked in the forefinger. She was discharged Jan. 26th, 1881.

\section{TOXTETH WORKHOUSE HOSPITAL, LIVERPOOL.}

STOKES'S SUPRA-CONDYLOID AMPUTATION.

(Under the care of Dr. LYSTER.)

For the following notes we are indebted to Mr. N. Roberts, M.B., C.M., house-surgeon.

T. $\mathrm{N}-$, aged sixteen, was admitted on Dec. 20th, 1879 , said to be suffering from erysipelas of the left leg. The previous history of the patient was that he had recently been discharged from a fever hospital, where he had been treated for typhus. He said that on admission into the fever hospital he had a little pain in this leg, which seems to have been due to a sore on one of the toes, resulting from the friction of a badly-fitting boot. It soon became evident, after admission into the Toxteth Hospital, that there was inflammatory mischief going on in the shaft of the tibia. Free incisions down to the bone were made, and the usual treatment for such a condition adopted with marked relief to the patient temporarily, but without materially affecting the progress of the disease, which now assumed a more chronic aspect than heretofore. Ere long it became evident that the bone was dead, and it only remained to wait for a separation of it from the living tissues, the boy being kept the while in as good a condition as good diet, cod-liver oil, and tonics could induce. By the month of May the condition of the leg was much worse, and it was telling so much upon the general health of the boy as to suggest operative inter. ference. The whole leg below the knee was very much swollen, with a large number of sinuses leading down to the new bone, through the cloacæ in which the dead bone could be felt by means of the probe, but the soft tissues of the limb were so involved, and their vitality so low as, together with the general condition of the patient, to make sequestrotomy a doubtful procedure, and to suggest amputation as the proper course to be adopted.

The particular operation resolved upon was Stokes's supracondyloid amputation of the thigh, which was performed by Dr. Lyster on June 3rd with highly satisfactory results. The operation was performed under strict Listerian antiseptics. The anterior oval flap containing the patella was easily obtained, and the cartilage of the patella was removed without much difficulty by the aid of the saw, supplemented by that of the bone forceps. The femur was divided threequarters of an inch above the articularsurfacefrom the patella, the surface of section being the dense cancellated tissue of the end of the bone. The vessels were tied by catgut ligatures, and a somewhat troublesome capillary oozing was controlled by deluging the flaps with hot carbolised water. The anterior flap was turned down, so that the patellar surface, denuded of its cartilage, was closely apposed to the sawn end of the femur, which apposition was further secured by means of a strong catgut ligature through the dense structures about the bones. The wound was closed by catgut ligatures, drainage-tubes were iatroduced, and the usual antiseptic dressings were applied. The patient was put to bed, and a sixth of a grain of morphia injected subcutaneously. The patient slept for five hours that night.

On the following morning the temperature was $99.8^{\circ}$, and in the evening $1002^{\circ}$.

On June 5 th the temperature in the morning was $99.8^{\circ}$; evening, $99^{\circ}$. From this time forward the temperature never rose above $99^{\circ}$.

The dressings were changed the day following the operation and on three other occasions before they were altogether discarded, which took place June 17th, the wound having then entirely closed with the exception of a slight superficial abrasion, and this healed up in a few days. The stump was entirely free from pain, even on moderately rough handling, at this early date. Two months after the operation he left the hospital, having been kept for some time so as to get used to his wooden leg, the stump being as perfect as any stump could be, and his general health excellent.

Remarks. - A point of some interest in this case is that an intractable disease seems to have been lighted up in the bone by an attack of typhus, in a lad otherwise healthy. This is sufficiently out of the common to merit. notice. On dissect. ing the leg, the entire shaft of the tibia was found to be necrosed and encased by the new bone, whilst the condition of the soft tissues showed that amputation was the only course that could have been pursued with any success.

\section{attediral Soxirtirs.}

\section{PATHOLOGICAL SOCIETY OF LONDON.}

Combined Carcinoma and Adeno-fibroma of the Breast.Hyaline Myxoma of Breast.-Cranium and Brain from a Hydrocephalic Adult. - Dermoid Tumour of Soft Palate._Lupus Erythematosus. - Squamous Epithelioma of Upper Jaw.

THE ordinary meeting of this Society was held on the 5th instant, Dr. Wilks, F.R.S., President, in the chair. It will be seen that a great variety of specimens were shown.

Mr. Rushton PARKer showed a specimen of Carcinoma and Adeno-fibroma of the Breast from a married woman, forty-two years of age, who came under his care in October, 1880. The growth had been noticed for three years. It occurred as a movable mass, the size of a walnut, in the upper part of the left breast; the nipple and lymphatic glands being free. He excised the growth, but as after removal it showed evidenee of being cancerous, the whole gland was removed. The age of the patient and the size of the growth were in favour of its being cancer, nor was its duration inconsistent with this view; but its mobility was in favour of its being a chronic mammary tumour, and had the patient been under thirty it might well have been thought to be of that nature. In dissecting the breast from the sub. jacent fascia a small bursa was met with, into which pro. jected a white nodule of adeno-fibroma. The structure of the main mass was that of adeno-fibroma, wavy fibrous tissue between acini and ducts; but in another lobe columns of aggregated cells within an alveolar stroma reproduced the characters of carcinoma. He supposed it was rare to find such a combination, but Langhans had recorded two cases; and he wished the specimen to be referred to the Morbid Growths Committee.

Mr. PARKER then showed a specimen of Hyaline Myxoma of the Breast, which had been noticed by the patient for about seven or eight years. It attained the dimensions of a good-sized orange, and occupied the upper and outer corner of the breast. It was a lobulated, gelatinous, opalescentlooking growth, with a central cyst, and several smaller cysts with intracystic growths. Some of the lobes were of a yellowish-white appearance, others glistening. Microseopically it was a pure adeno-myxoma, and was peculiar in its hyaline character, differing from the more common variety of the softer chronic mammary tumours, with myxomatous stroma. He also showed some microscopical specimens of Adenoma of the Breast. One was from a patient sixty-three years of age, and showed fibro-alveolar arrangement with spaces containing sebaceous material varying in size from a pin's head to half the diameter of a pea. $\mathrm{He}$ remarked that increasing pathological knowledge showed that these growths were not so rare as used to be thought. Another specimen was of an intracystic protrusion from a simple cyst of the breast. It appeared as if a sort of hernia of the mammary gland substance had occurred into the cyst in consequence of a blow. He also showed section of an adenoma of the tongue. It grew at the back part of the organ in a young woman, and was a pure adenoma-a very rare disease. Another adenoid growth was one which grew between the skin and mucous membrane of the nose of a man sixty-seven years of age. It was of three or four years' duration, and exhibited round-celled infiltration between the acini.-Mr. BuTLIN said that the portion of the growth under the microscope in the first case was undoubtedly car. 